\title{
Cloning and Characterization of Undaria pinnatifida Suringar Phytoene Desaturase Gene Enhancing Carotenoid Accumulation in Transgenic Tobacco
}

\author{
Tengteng Guan ${ }^{1}$, Hongmin $\mathrm{Xu}^{1}$, Yi Ma ${ }^{1}$, \\ Yinjie $\mathrm{Li}^{1}$, Tengteng Guan ${ }^{1}$,
}

\author{
${ }^{1}$ College of Life Sciences, Qingdao University, Qingdao 266071, China
}

\begin{abstract}
The phytoene desaturase is a key enzyme involved in the carotenoid biosynthesis pathway, which catalyzes the conversion of $\zeta$-carotene from phytoene. In this study, he PDS gene (UpPDS) was isolated and characterized from Undaria pinnatifida Suringar, the full-length cDNA sequence was 1707 bp in length and encoded 568 amino acid residues. Then, the plant expression vector pCAMBIA2300-UpPDS was constructed and transformed into Agrobacterium LBA4404, and then transferred into tobacco plants by infection. Transgenic tobacco plants were identified by PCR amplification and southern blotting. Assay of real-time quantitative PCR ananlysis indicated that the expression level of the target gene UPPDS differed greatly in different transgenic tobacco plants. Spectrophotometry was used to determine the carotenoids content in the leaves trangenic plants, and the results showed that the content of carotenoids in the leaves of transgenic plants was higher than that of wild tobacco, and the maximum content increased 1.13 times compared with that of wild plants.
\end{abstract}

Keywords: Undaria pinnatifida Suringar, Phytoene Desaturase (PDS), Gene Cloning, Functional Expression, Transgentic Tabacoo

\begin{abstract}
Introduction
Carotenoids are ubiquitous in nature and widely found in higher plants, algae, photosynthetic bacteria and some non-photosynthetic microorganisms[1-2]. Carotenoids, as natural pigments necessary for animals, play a very important role in daily life activities. According to reports, carotenoids can reduce the damage of active oxygen free radicals to the human body [3] and have significant antioxidant activity [4]. In addition, carotenoids also have the effect of improving immunity[5-6] and delaying aging[7-8]. Fucoxanthin is a major carotenoid component, accounting for more than $10 \%$ of the total carotenoid production [9]. As a type of light-reinforcing pigment in algae, it can reduce the cells caused by the photAooxidation of chlorophyll Injury, but also has the physiological functions of weight loss, bacteriostasis, cancer prevention[10-11].
\end{abstract}

The carotenoid biosynthesis pathway was first discovered in higher plants, but at present people have not fully understood the catalytic mechanism of key enzymes in the carotenoid biosynthesis pathway in plants[12].Due to the less catalytic enzyme content and weaker activity in the carotenoid metabolic pathway, resulting in fewer carotenoid metabolites, there are great difficulties in the purification of catalytic enzymes and the determination of enzyme activity during carotenoid metabolism[13]. Phytoene desaturase (PDS) is the main rate-limiting enzyme in the synthesis of carotenoids. This enzyme catalyzes the conversion of phytoene into $\zeta$-carotene, which is further catalyzed by other enzymes to synthesize the chain carotenoids such as spore red, lycopene and $\beta$-carotene [9]. Carotenoids, as a component of the photoprotective light-harvesting complex, have the effect of protecting chloroplasts [14]. When the PDS gene is silenced, carotenoid synthesis is inhibited, chloroplasts lose their carotenoid protection and degrade, and the leaves appear yellowed or even whitish. This phenomenon is called photobleaching [15]. Since the photobleaching phenomenon can be directly observed by the naked eye, the phytoene desaturase (PDS) has been frequently used as a reporter gene in virus-induced gene silencing transformation systems in recent years [16].

$U$. pinnatifida is known as the "king of seaweed". It is rich in minerals, vitamins and pigments. It has high nutritional value and strong environmental adaptability. It has great development and utilization value. Studies have shown that $U$. pinnatifida has various effects such as diminishing swelling, eliminating fat accumulation,

This article is published under the terms of the Creative Commons Attribution License 4.0

Author(s) retain the copyright of this article. Publication rights with Alkhaer Publications.

Published at: http://www.ijsciences.com/pub/issue/2020-07/

DOI: 10.18483/ijSci.2359; Online ISSN: 2305-3925; Print ISSN: 2410-4477 
eliminating free radicals, antioxidant and protecting nerve cells [17]. Relevant research reports that fucoxanthin is the main carotenoid in Fucophyllum seaweed, the fucoxanthin content in $U$. pinnatifida is higher than the fucoxanthin content in Laminaria. japonica and Fistulifera solaris[18]. In recent years, the development and utilization of bioactive substances such as alginic acid and saponin in $U$. pinnatifida have become a hot research field. Therefore, $U$. pinnatifida has been used as an excellent source for the extraction and production of fucoxanthin, and has been carried out for the biosynthesis of fucoxanthin Research has important theoretical value and application prospects. In the present study, we isolated and cloned the cDNA of $U p P D S$ from $U$. pinnatifida, and analyzed the amino acid sequence of the enzyme. Meanwhile, $U p P D S$ was introduced intovan appropriate vector and overexpressed in tobacco by Agrobacterim - mediated transformation to finalize its capability. This research would increased the production of carotenoids in other crops.

\section{Materials and Methods Materials}

$U$. pinnatifida was collected from the seaside of Qingdao in May 2017. Cleaned up with distilled water, dried water, cut into small pieces, and then quickly placed in liquid nitrogen followed by immediate storage at $-80^{\circ} \mathrm{C}$ refrigerator for RNA isolation. Ordinary tobacco (K326) was utilized as the receptor in the transformation process.

\section{Cloning of $U p P D S$ from $U$. pinnatifida Suringar}

Total RNA was extracted from $U$. pinnatifida using RNAprep Pure Plant Kit (TianGen, Beijing, China) according to manufacturer's instructions. The quality of RNA was determined by agarose gel electrophoresis. The first strand cDNA synthesis kit was used to synthesize the first strand of complementary DNA (cDNA) from $2 \mu \mathrm{g}$ of total RNAs using oligo (dT) primers according to the manufacturer's instructions (TaKaRa, China). The cDNA was synthesized through PrimeScript Kit II 1st Strand cDNA Synthesis Kit (TaKaRa, Osaka, Japan) according to the manufacturer's instructions, using moderate total RNA as template and Oligo (dT) as primer. PCR was performed using the cDNA as template according to the following program: denaturation at $94^{\circ} \mathrm{C}$ for $3 \mathrm{~min}$, followed by 32 cycles each of denaturation at $94^{\circ} \mathrm{C}$ for $45 \mathrm{~s}$, then $56^{\circ} \mathrm{C}$ for $45 \mathrm{~s}$ and $72^{\circ} \mathrm{C}$ for $1 \min 10 \mathrm{~s}$, followed by a $10 \mathrm{~min}$ final extension at $72^{\circ} \mathrm{C}$. The PCR product was purified and cloned into pMD18-T vector for sequencing.

Construction of Plant Expression Vectors and tobacco transformation

A pair of primer (PDScF : 5' TTGCCTGCTCCTCTGAAC- 3'; and PDScR : 5' ATGAGTCCGATGCCGAAC - 3') were designed to amplify the ORF of UpPDS using the full-length cDNA as template according to the PCR program mentioned above, and PCR product was cloned into pMD18-T to construct pMD18-UpPDS for sequencing. ORF was isolated from pMD18-UpPDS by digestion of BamHI and $X b a \mathrm{I}$, and then cloned into plant expression vector PCAMBIA2300 to construct pCAMBIA2300-UpPDS for sequencing. The plasmid pCAMBIA2300-UpPDS was introduced into the tobacco genome by Agrobacterium infection method. Tobacco leaf discs infected with LBA4404 were transferred to differentiation medium (MS $(0.1 \mathrm{mg} / \mathrm{mL}$ NAA and 1 $\mathrm{mg} / \mathrm{ml} \mathrm{6-BA)).} \mathrm{These} \mathrm{media} \mathrm{were} \mathrm{incubated} \mathrm{in} \mathrm{the} \mathrm{dark}$ 2 days at $25^{\circ} \mathrm{C}$ with a $16 / 8 \mathrm{~h}$ (light/dark) photoperiod. Then transfer to selection medium (MS (half intensity MS containing $100 \mathrm{mg} / \mathrm{L}$ kanamycin and $500 \mathrm{mg} \mathrm{L} / 1$ carbenicillin)) to select transformants. Then transfer to root induction medium (half intensity MS containing $50 \mathrm{mg} \mathrm{L} / 1$ kanamycin and $250 \mathrm{mg} / \mathrm{L}$ carbenicillin). After the roots are developed, the transformed shoots are numbered to produce a $\mathrm{T} 1$ generation.

\section{Genomic PCR and southern blotting analysis}

Total DNA from transgenic and non-transgenic plants was amplified according to the CTAB method. The purity and concentration of obtained genomic DNA were measured by SmartSpec Plus Spectrophotometer. Transformants were screened by the PCR analysis using the genomic DNA as the template.

As for southern blotting analysis, Hybridization and immunological detection were conducted with DIG Probe Synthesis Kit (Roche, Mannheim, Germany) and Detection Strarter Kit II (Roche, Mannheim, Germany) According to the instruction. approximately $10 \mu \mathrm{g}$ of genomic DNA was digested by BamHI and XbaI. electrophoresed on agarose gel and subsequently transferred to a positively charged nylon membrane by Capillary siphoning phenomenon (Roche, Mannheim, Germany).

\section{Real-time quantitative PCR}

Real-Time Quantitative RT-PCR was used to determine expression of UpPDS Gene in Transgenic Tobacco. RNA extraction kit (polysaccharide polyphenol plant tissue RNA extraction kit) was used to extract total RNA from leaves of the same site of transgenic tobacco and wild-type tobacco, and reverse transcription of cDNA with reference to Aidlab's kit (TURE script 1st Stand cDNA SYNTHESIS Kit). With $N t U I B$ as the internal reference gene, the reaction system of qRT-PCR is $10 \mu \mathrm{L}$, containing $5 \mu \mathrm{L}$ of SYBR Green SuperMix $(2 \times), 0.5 \mu \mathrm{L}$ each of the forward and reverse primers, $1 \mu \mathrm{L}$ of cDNA and $5.0 \mu \mathrm{L}$ of $\mathrm{ddH}_{2} \mathrm{O}$. Amplification conditions were: $95^{\circ} \mathrm{C}$ for $3 \mathrm{~min}, 95^{\circ} \mathrm{C}$ for $15 \mathrm{~s}, 60^{\circ} \mathrm{C}$ for $30 \mathrm{~s}, 39$ cycles. Each sample was sampled 3 times and each set was repeated 3 times.

\section{Determination of lycopene in Transgenic tobacco}

Because lycopene is unstable and easily decomposed by light, its extraction and determination are performed as far as possible under dark conditions. Extraction and determination of lycopene refer to the method of 
Gangat[19]. The frozen leaf powder was suspended in anhydrous ethanol, and then the solution was incubated at $35^{\circ} \mathrm{C}$ for $4 \mathrm{~h}$. The remaining residue was added to an appropriate amount of anhydrous ethanol and extracted twice, and finally the volume was adjusted to $10 \mathrm{ml}$. The lycopene content was measured at a wavelength of $502 \mathrm{~nm}$ on a Shimadzu UV-2501 PC spectrophotometer (Shimadzu, Germany).

\section{Results}

Isolation of the full-length $U p P D S$ cDNA from $U$. pinnatifida Suringar

The full-length cDNA sequence of the PDS gene was amplified (Figure.1). It consisted of a 1707bp open reading frame (ORF) that encodes 568 amino acid residues with a predicted molecular weight of $62 \mathrm{kDa}$, and the isoelectric point (pI) was 5.79 (Figure.2). The molecular formula of phytoene desaturase encoded by the UpPDS gene was $\mathrm{C}_{2803} \mathrm{H}_{4409} \mathrm{~N}_{737} \mathrm{O}_{808} \mathrm{~S}_{29}$, and the instability coefficient of phytoene desaturase was 37.65 , indicating that the protein was a stable protein. The total average hydrophilicity (GRAVY) of UpPDS protein was -0.012 , indicating it belonged to a class of stable hydrophilic proteins.

\section{Molecular characterization of the transgenic tobacco \\ The coding region of $U p P D S$ was constructed into plant expression vector pCAMBIA2300.The genomic DNA extracted from transgenic plants was used for PCR analysis to verify the presence of the target fragment, However, DNA samples from control plants did not have any PCR product (Figure.3A). Southern blot analysis was performed to confirm the integration of the PDS transgene in the transformed tobacco genome in a single copy (Figure.3B).}

\section{Real-time quantitative PCR detection in transgenic tobacco}

The real-time fluorescence quantitative detection method was used to verify the expression of $U p P D S$ gene in transgenic tobacco. As can be seen from the figure.4, the expression of $U p P D S$ gene was not detected in non-transgenic tobacco, but $U p P D S$ was expressed in transgenic tobacco. However, the expression levels of the UpPDS genes of different transgenic tobaccos are also different, and the expression level is the highest in the second transgenic tobacco, which is statistically significant compared with WT $(\mathrm{P}<0.01)$.

\section{Accumulation analysis of carotenoids in transgenic tobacco}

In this experiment, a single organic solvent, absolute ethanol, was used to extract lycopene. The content of the extracted pigment was about $15 \%-25 \%$. The absorption peak at $502 \mathrm{~nm}$ was selected to avoid the interference of $\beta$-carotene and other components on the results. It can be seen from the figure.5 that the carotenoids content of transgenic tobacco plants is higher than that of non-transgenic tobacco plants, but the increase in the size of each transgenic tobacco plant is different. Among them, the number 2 transgenic tobacco plant is the highest, which increases by about 1.13times.

\section{Discussion}

Carotenoids, as a prerequisite for vitamin A, cannot be synthesized by animals, and must be taken from the diet in order to meet daily life activities[20].Through genetic manipulation, it is possible to breed crops with higher carotenoid content. This study evaluated the effect of transforming UpPDS gene on carotenoid content in model biological plant tobacco, and provided a molecular basis for the next step to develop highly nutritious transgenic food crops [21]. In the present study, we successfully isolated $U p P D S$ gene from $U$. pinnatifida for the first time and analyzed its sequence, structure, transcript level and overexpression. The protein molecular weight was predicted to be $62 \mathrm{kDa}$ and the isoelectric point (pI) was 5.79. The molecular formula of phytoene desaturase encoded by the UpPDS gene was $\mathrm{C}_{2803} \mathrm{H}_{4409} \mathrm{~N}_{737} \mathrm{O}_{808} \mathrm{~S}_{29}$, and the instability coefficient of phytoene desaturase was 37.65, indicating that the protein was a stable protein. The total average hydrophilicity (GRAVY) of UpPDS protein was -0.012 , indicating it belonged to a class of stable hydrophilic proteins. The presence of the putative signal peptide in the $\mathrm{N}$ - terminus for plastid localization was typical of all the enzymes involved in the carotenoid biosynthesis in plants [22].

The expression levels of the different UpPDS transgenic tobacco obtained in this paper are significantly different, which may be related to the position of the gene inserted into the tobacco chromosome. The expression level of the UPPDS gene was positively correlated with the carotenoids content of the plants. Among them, the expression level of transgenic tobacco 2 was the highest, and its carotenoids content was also the highest, which was about 1.13 times higher than that of the non-transgenic control plants. This shows that the UPPDS gene derived from seaweed also has the activity of controlling carotenoid synthesis in terrestrial higher plants.

\section{Figure legends}

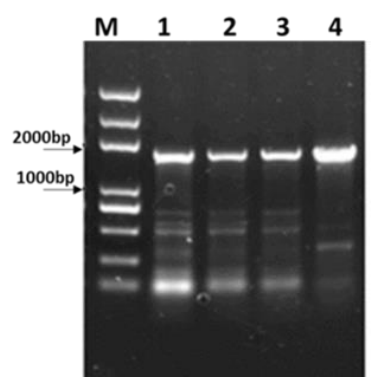

Figure. 1 Isolation of the full-length $U p P D S$ cDNA from $U$. pinnatifida Suringar 
Cloning and Characterization of Undaria pinnatifida Suringar Phytoene Desaturase Gene Enhancing Carotenoid Accumulation in Transgenic Tobacco

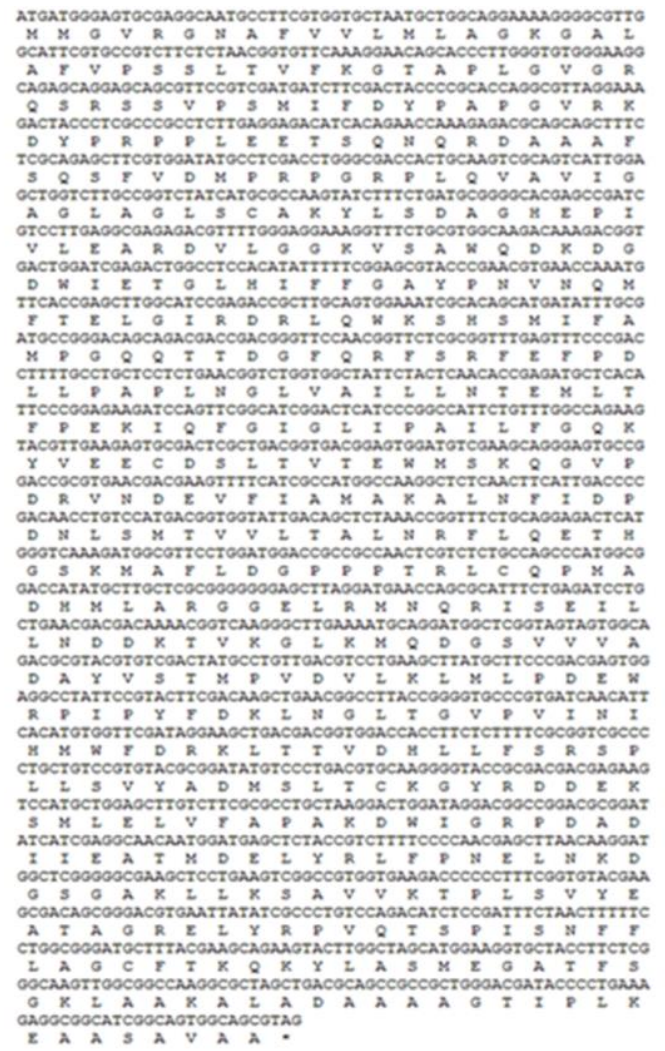

Figure. 2 The nucleotide sequence and predicted amino acid sequence of the $U P P D S$ gene

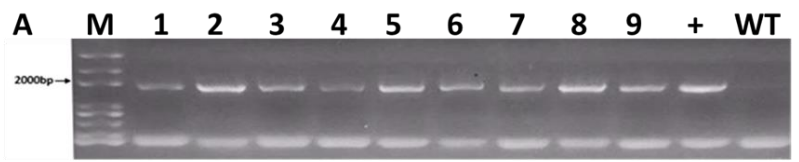

B WT L1 L2 L3 L5 L8

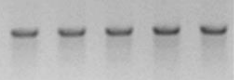

Figure.3 Confirmation and analysis of transgenic tobacco expressing $U p P D S$

A. PCR analysis of the transgenic plants with UpPDS. M, DNA marker III. Lanes 1-9, transformed lines. PCR products (1707bp) corresponding to $U p P D S$ were amplified; Lane 10, positive control; Lane 11, empty vector plant.

B. Southern blotting analysis to confirm the presence of UpPDS. Southern blotting of BamHI and $X b a \mathrm{I}$ cut genomic DNA probe with $U p P D S$ fragment; Lane1 WT, non-transgenic tobacco; Lane 1 empty vector plant; Lanes 2-5 transgenic Lanes L1, L2, L3, L5 and L8

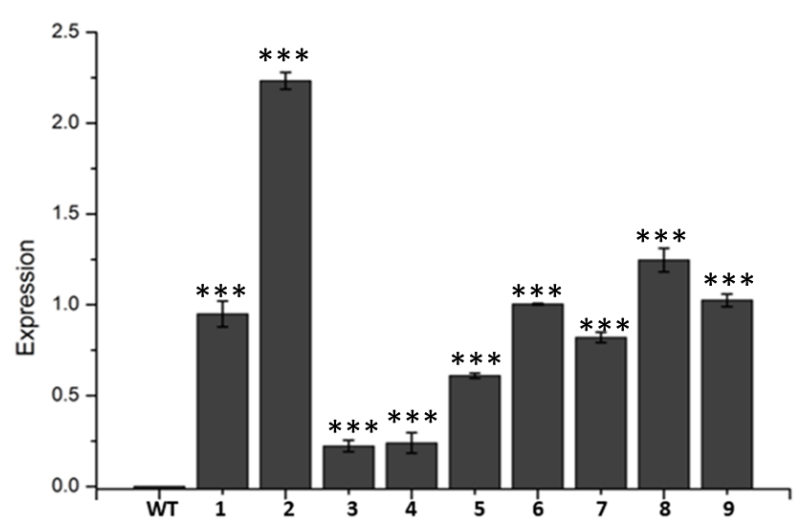

Figure. 4 Quantitative real-time PCR analysis of UpPDS transcripts.

Data represents the average of three independent expressions $\pm \mathrm{SE}$, asterisks above the column indicate significant differences in comparison with the $\operatorname{control}(* * * \mathrm{P}<0.01)$

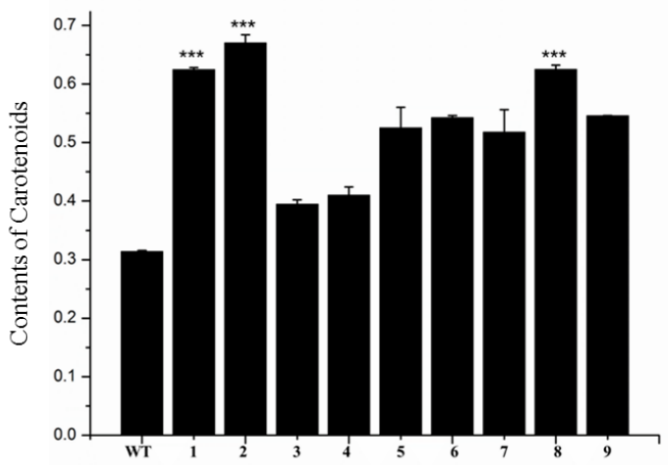

Figure. 5 Contents of carotenoids in transgenic.

Each value represents the mean \pm standard error (SE)of three samples.

\section{References}

1. Caterina, D., et al., Virtually complete conversion of lycopene into $\beta$-carotene in fruits of tomato plants transformed with the tomato lycopene $\beta$-cyclase (tlcy-b) cDNA. Plant Science, 2004. 166(1): p.0-214.

2. Tao, L., et al., A carotenoid synthesis gene cluster from Algoriphagussp. KK10202C with a novel fusion-type lycopene $\beta$-cyclase gene. Molecular Genetics \& Genomics, 2006. 276(1): p.79-86.

3. Claire, B., et al., Pubertal delay. La Revue Du Praticien, 2008.58(12): p.1326-1330

4. Heinecke, J.W., et al., Oxidants and antioxidants in the pathogenesis of atherosclerosis: Implications for the oxidized low-density lipoprotein hypothesis. Atherosclerosis, 1998. 141(1): p.1-15.

5. Desouza, M., et al., Carotenoid Biosynthesis. Subcell Biochem, 
2003. 79: p.199-217.

6. Meléndez, M., et al., A comprehensive review on the colorless carotenoids phytoene and phytofluene. Archives of Biochemistry and Biophysics, 2017. 572(2015): p.188-200.

7. Wilhelm, S., et al., Supplementation with tomato-based products increases lycopene, phytofluene, and phytoene levels in human serum and protects against uv-light-induced erythema. International Journal for Vitamin and Nutrition Research, 2005. 75(1): p.54-60.

8. Khachik, F., et al., Chemistry, distribution, and metabolism of tomato carotenoids and their impact on human health. Experimental Biology and Medicine, 2002. 227(10): p.845-851.

9. Breitenbach, J., et al., Catalytic properties of an expressed and purified higher plant type zeta-carotene desaturase from Capsicum аппиит. European Journal of Biochemistry, 2010.265(1): p. 376-383.

10. Miyashita, K., et al., The allenic carotenoid fucoxanthin, a novel marine nutraceutical from brown seaweeds. Journal of the science of food and agriculture, 2011.91(7): p.1166-1174.

11. Peng, J., et al., Fucoxanthin, a Marine Carotenoid Present in Brown Seaweeds and Diatoms: Metabolism and Bioactivities Relevant to Human Health. Marine Drugs, 2011. 9(12): p.1806-1828.

12. Simkin, A.J., et al., Light-dark regulation of carotenoid biosynthesis in pepper (Capsicum annuum) leaves. Journal of Plant Physiology, 2003.160(5): p.0-443.

13. Dewir, Y.H., et al., A simple method for mass propagation of Spathiphyllum cannifoliumusing an airlift bioreactor. Vitro Cellular \& Developmental Biology Plant, 2006. 42(3): p.291-297.
14. Fofana, I., et al., A geminivirus-induced gene silencing system for gene function validation in cassava. Plant Molecular Biology, 2004.56(4): p. 613-624.

15. Kumagai, M.H., et al., Cytoplasmic inhibition of carotenoid biosynthesis with virus-derived RNA[J]. Proceedings of the National Academy of Sciences of the United States of America, 1995. 92(5): p. 1679-1683.

16. Fu, D.Q., et al., Enhancement of virus-induced gene silencing in tomato by low temperature and low humidity. Molecules and Cells, 2006. 21(1): p.153-160.

17. Kimura,J., et al., New loliolide derivatives from the brown alga Undaria pinnatifida. Journal of Natural Products, 2002.65(1): p.57-8.

18. Breitenbach, J., et al., A higher-plant type zeta-carotene desaturase in the cyanobacterium Synechocystis PCC6803. plant molecular biology, 1998. 36(5): p.725.

19. Davuluri, G.R., et al., Fruit-specific RNAi-mediated suppression of DET1 enhances carotenoid and flavonoid content in tomatoes. Nature Biotechnology, 2005. 23(7): p.890-895.

20. Mueller, L., et al., Antioxidant activity of $\beta$-carotene compounds in different in vitro assays. Molecules, 2011. 16(12): p. $1055-1069$.

21. Ralley, L., et al., Metabolic engineering of ketocarotenoid formation in higher plants. Plant Journal for Cell \& Molecular Biology, 2004. 39(4): p. 477-86.

22. Araya, J.M., et al.,cDNA cloning of a novel gene codifying for the enzyme lycopene $\beta$-cyclase from Ficus carica and its expression in Escherichia coli. Appl Microbiol Biotechnol, 2011. 92(4): p.769-77. 